\title{
Research on the evaluation system of College Students' practice ability -- Based on the "three oriented" talent cultivation mode
}

\author{
Hui $\mathrm{Ji}^{1}$, Tao $\mathrm{Li}^{1}$, Hua Tian ${ }^{2, a}$ \\ ${ }^{1}$ Department of Basic Medicine School, Qiqihar Medical University, Qiqihar, Heilongjiang Province, \\ China, 161006. \\ 2Department of Pharmacology, Qiqihar Medical University, Qiqihar, Heilongjiang Province, China. \\ 161006 \\ atianhua0912@163.com
}

Keywords: College students; practice ability; three oriented; evaluation system; research

\begin{abstract}
With the system of education reform in China and the continuous progress of the implementation of the policy of university enrollment, college students gradually become the main force of social construction and development, and college students' practice ability, has become a good evaluation of students or key indicators. "Three oriented" talent training model is to focus on the future development of students as the goal, by allowing students to participate in teaching management, to improve the ability of College students. In this paper, based on the "three oriented" talent training model, the paper discusses the evaluation system of College Students' ability of practice, which aims to provide reference for related research. Since the enrollment expansion in 1999, the number of university graduates in China increased year by year, in 2016 the total number of college graduates nationwide more than 7 million 500 thousand people, a new record high, the contradiction between supply and demand of talent market is becoming increasingly fierce, the employment pressure gradually increases. And the students"s ability to practice becomes the key factor whether they can get out of school, go to the society, and have a place in society. With the continuous deepening of the reform of the education system, gradually enhance campus democracy consciousness, the future development of the students "as the goal of the" three oriented "applied talents training mode of advancing, the dominant position of students is more and more high. In application-oriented training in colleges and universities, students' practice ability and the composition and evaluation of the research and development of system and culture, it is of special significance for the long-term development of educational reform and school.
\end{abstract}

\section{Introduction}

The evaluation system of practice ability of college students in the development of our country still belongs to the initial stage, but in Europe the labor market has been relatively mature, the application is to help an important tool for policy analysis and human resources management of. Generally speaking, the practice ability of college students is a kind of ideal to meet the social needs, employment and personal value and obtained during the study at the university through the study of professional knowledge and their comprehensive quality training. The practice ability of college students can also be referred to as the college students' employ ability, which covers a wide range, many college students belong to the comprehensive professional skills, rather than a single ability, such as China often say that the learning ability, innovation ability, logical thinking ability, adaptation ability, practice ability, survival ability, job skills etc. all belong to the category of practice ability.[1]

\section{Three oriented" talent training mode}

The "three oriented" training mode is to cultivate students occupation morality, cultural quality, physical and psychological quality and practice ability as the main content, to the future development 
of the students training objectives, including three modules: the module of humanistic quality education in "occupation emotion oriented, with" professional ability oriented "professional quality training module and the" social "oriented physical and mental quality development module. Among them, occupation emotion is the essential quality of every student in the future, students always remember the spirit of dedication, love, and foundation to realize the individual value; practice ability is a kind of meet the needs of the society, the ability to achieve the ideal employment and personal values of students obtained through the study of professional knowledge and their comprehensive quality training students; social adaptation is entering society, positive start work and ability to adapt to a rapidly. The model was put forward three culture oriented talents, by domestic scholars and universities alike, this is because the "three oriented" talent cultivation mode is to cultivate the core meaning of occupation moral, professional and technical skills, ability to adapt to society's high quality talents of modernization.

\section{The establishment of evaluation system}

Elements of the practice ability. Although the practice ability evaluation system in the development of our country still belongs to the initial stage, but from the analysis of the existing data, basically can be college students' practice ability is divided into two parts: the ability of hard and soft skills. Among them, hard ability refers to the professional knowledge, skills and experience. That is, can be given in certain criteria such as the human resources management center of the college students during the annual examination results, examination certificate and its graduate school level as the main standard to measure college students' personal ability. Soft capability refers to the individual students with innovation ability, learning ability, logical thinking ability, team spirit, personality characteristics, the ability cannot be determined by a simple assessment, but it is very important in the practice of the personal qualities of College students. For the soft ability of college students, the human resource management center of HR often through the face-to-face communication with the candidates to figure out and investigate.

As a unit, for the recruitment of fresh graduates and college students in the survey results, the graduates should have the ability and the quality of the problem, and most of the students think that the recruitment unit level of professional knowledge is the most important key factors for them. In spite of this, some people put forward different opinions. Rennes University of China School of management has been a recruitment unit of satisfaction survey by college students, the results of this survey, the majority of college students, has basically mastered the necessary professional basic professional quality and professional ability, the level of professional knowledge can basically meet the market and the requirement of post graduates in the work, can do professional daily work they are familiar with. Not only that, then another on "the degree of satisfaction of college students professional knowledge evaluation" employer survey results soon again to prove this conclusion, the survey results show that employers on College Students' professional knowledge is very satisfied with the situation accounted for $2.78 \%$, compared with the general accounting for $66.67 \%, 30.56 \%$. In other words, excluding the normal level of professional knowledge, the yielding ability of college students is the main factor that should be included in the evaluation system of College Students' practice ability. At the same time, combined with the cultivation of the core modes and the training goal of three oriented talents, we will overview the evaluation system for the four core elements, 15 entries, followed by the employment of college students ability (employment process familiarity, resume production skills, interview skills, coping skills, employment and occupation planning, team) the ability of cooperation (interpersonal, teamwork, positive personality) and innovation ability (innovation, adaptability) and the students' individual qualities (ambition, sense of responsibility, understanding, rapid response), full set of 100 points, the specific index connotation and fractional set are shown in table 1.[2] 
Table 1 Evaluation System of College Students' practice ability -- Based on the "three oriented" talent cultivation mode

\begin{tabular}{|c|c|c|}
\hline $\begin{array}{l}\text { First grade index and the share } \\
\text { value }\end{array}$ & Two indicators and the score & Index connotation \\
\hline \multirow{6}{*}{$\begin{array}{l}\text { Ability to apply for a job (40 } \\
\text { points) }\end{array}$} & $\begin{array}{l}\text { Familiarity with employment } \\
\text { process ( } 5 \text { points) }\end{array}$ & $\begin{array}{c}\text { Familiar with the employment } \\
\text { process and progress }\end{array}$ \\
\hline & Resume making skills (5 points) & Resume features distinctive \\
\hline & Interview skills (5 points) & $\begin{array}{l}\text { Excellent interview thinking } \\
\text { mode }\end{array}$ \\
\hline & Coping skills (10 points) & Answer questions with skill \\
\hline & Employment situation (5 points) & Large market demand \\
\hline & Career planning (10 points) & $\begin{array}{l}\text { Have a clear career orientation } \\
\text { and goals }\end{array}$ \\
\hline \multirow{3}{*}{ Team work ability (20 points) } & $\begin{array}{l}\text { Interpersonal communication } \\
\text { (10 points) }\end{array}$ & Be good at \\
\hline & Team work (5 points) & Strong sense of teamwork \\
\hline & Positive personality (5 points) & Cheerful upward \\
\hline \multirow{2}{*}{ Innovation ability (20 points) } & Innovation (10 points) & strong \\
\hline & Adaptability (10 points) & strong \\
\hline \multirow{4}{*}{ Individual quality (20 points) } & Upward mobility (5 points) & Positive progress \\
\hline & Sense of responsibility (5 points) & strong \\
\hline & Comprehension (5 points) & strong \\
\hline & Quick response (5 points) & Agile thinking \\
\hline
\end{tabular}

The content of an evaluation system. Job search ability refers to the ability of the applicant to find and obtain the position in the social current market conditions. Including search job information, screening job information, the use of job information processing capabilities. Job seekers in the job search process to understand and give attention to national policies, laws and regulations, the current situation of the market industry, employing units and other information. While job seekers in the use of these information, we should do the following: first, to ensure the accuracy of information and authenticity; secondly the job should have pertinence and applicability; continuity and systematization again to grasp the information; finally, in order to plan organized, clear. Only in this way, job seekers can be Zhandexianji in which a galaxy of talents in the society, to survive and develop under the tremendous pressure of market competition.[3]

Team cooperation ability refers to base on the group, the mutual cooperation between the team and the work efficiency can reach the maximum in the team, able to do each other, complementary advantages. For team members, each member must be loyal to the team, the team to comply with the rules and order in the team, we need to show the ability of individuals and individuals with other members of the formation of a tacit agreement in different positions, mutual coordination and cooperation. Teamwork is very important. It has a huge role in promoting team building and development. Team spirit is not merely the performance of individual work and results, but also emphasizes the achievements of the team as a whole, it is more conducive to the growth of individuals and teams.

Innovation ability is the theory and practice, the development of science and technology, the combination of art and life, and provide economic value and social value in a variety of industries, including the ability of new ideas, new trend, new forms and new things of value. Innovation is the core and soul of domestic progress, social development and economic competition. In today's society, competition does not be too much the competition of talents as the competition of innovation ability. Innovation includes scientific and technological innovation, institutional innovation, cultural innovation, formal innovation, management innovation, marketing innovation, strategic innovation, etc.. Therefore, innovation is the primary driving force for social development and progress.

Individual characteristics can also be referred to as personality characteristics, which refer to the individual in the psychological development of the gradual formation of a stable psychological characteristics. For example, individual characteristics of the wolf team showed strong dedication 
and enterprising spirit, the pursuit of excellence; loyalty, loyalty to the boss, loyalty to the team; concentrate on the job of the ability of enterprises and improve the ability of service;

Strong sense of social responsibility. Negative personality characteristics often affect individual behavior, such as quit, encounter difficulties every cringe; nothing, no goal, no direction have neither learning nor skill; poor people and egoistic. This will have a serious impact on work efficiency and performance, more serious, will affect the individual's living state and emotional state and will bring disaster to others. Therefore, the ability of enterprises to assess, should be combined with the job requirements and character test results for a comprehensive consideration.The grading standards of the evaluation results can be divided into 4 grades: excellent, good, qualified and unqualified.[4]

\section{Summary}

The core meaning of "three oriented" personnel training mode is tantamount to cultivate the talents with high professional and technical ability, strong social adaptability and high professional ethics. This paper discusses the "three oriented" personnel training model based on the students"s participation in the research on the evaluation system of College Students' professional ability. College students' practice ability is not only reflected in the students"s mastery of professional knowledge, professional skills, moral accomplishment and social experience, but also in innovation ability, learning ability, logical thinking ability, team spirit, social ability etc.. Therefore, to establish and perfect the students to participate in the "three oriented" training mode on the basis of research should focus on the practice ability of the students' evaluation system, gradually establish and perfect the evaluation system of professional ability of college students, to create more quality development and social practice for every student the opportunity to promote the cultivation of practice ability of students, schools and teachers should use a variety of educational resources, as much as possible to create conditions for students, cultivate students' practice ability. For the study of College Students' practice ability evaluation system can fully grasp the quality of teaching, but also to the evaluation of college students comprehensive professional ability, to help schools and teachers for the teaching reform of physical training mode innovation, also provides a reference for the evaluation of the practice ability of students and schools.

\section{Acknowledgment}

1 Heilongjiang Province Planning Office Youth special name: "students as the center" perspective of college students to participate in teaching management research, project number: JGD1215052

2 "three oriented" "teaching and learning evaluation" special bidding project, the name of the "three oriented" practice ability evaluation system research and construction, project number: JGZB160201 3 Heilongjiang Provincial Institute of higher education, the name: the construction of teaching organization and teaching management system reform in Colleges and universities, project number: 16Q161

Institute of higher education "in Heilongjiang Province in 13th Five-Year 4" higher education research project name: research and application, evaluation of teaching in experimental teaching based on the project number: 16G265

5 Heilongjiang Provincial Institute of higher education planning project, the name: the construction of excellent teaching team of basic medicine in Colleges and universities, project number: 16G293

\section{References}

[1] Fu J, professor, Supervisor D, et al. The Talent Cultivation Mode in Research-oriented Four-year Universities: Problems and Improvement Strategy[J]. Educational Research, 2010, 62 suppl:136-48.

[2]Alsinet T, Barroso D, Béjar R. A FORMAL MODEL AND SUPPORT SYSTEM FOR THE CONTINUOUS EVALUATION OF COMPETENCES[J]. Astronomy \& Astrophysics, 2010, 567(2):3733-3741. 
[3]White J W, Andrade-Sanchez P, Gore M A, et al. Field-based phenomics for plant genetics research[J]. Field Crops Research, 2012, 133(4):101 - 112.

[4]Kruska R L, Reid R S, Thornton P K, et al. Mapping livestock-oriented agricultural production systems for the developing world[J]. Agricultural Systems, 2003, 77(1):39-63. 